\title{
Effectiveness of red dichromatic imaging for dissection of the submucosal layer when hematoma is encountered
}

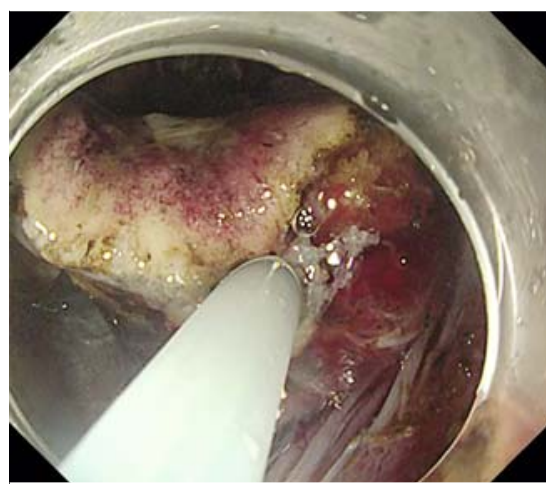

- Fig. 1 Endoscopic submucosal dissection for gastric tumor in a 72-year-old man. Hematoma in the submucosal layer was caused by the submucosal injection.

Endoscopic submucosal dissection (ESD) for gastric tumors is performed worldwide. When vascularized lesions are treated, hematoma in the submucosal layer is sometimes encountered during dissection. The presence of submucosal fibrosis and hematoma often makes dissection very difficult because identifying the correct submucosal tissue plane is almost impossible despite attempts at washing using the scope's water jet function. Red dichromatic imaging (RDI; Dual Red Imaging) is a recently released novel image-enhanced endoscopic technology (Olympus Medical Systems, Tokyo, Japan) [1-4]. We report a case in which RDI helped identify submucosal fibrous tissue in the submucosal layer with hematoma during gastric ESD.

A 72-year-old man with a gastric tumor was referred to our hospital. ESD was performed using an electrosurgical knife (IT2 knife; Olympus Medical Systems) and therapeutic gastroscope (GIF-H290 $T$ with EVIS X1 video system; Olympus Medical Systems). A circumferential incision was made and the submucosal layer subsequently dissected. However, the submucosal injection caused bleeding in the submucosal layer, leading to submucosal hematoma ( $\vee$ Video 1 ; $>$ Fig. 1 ). In
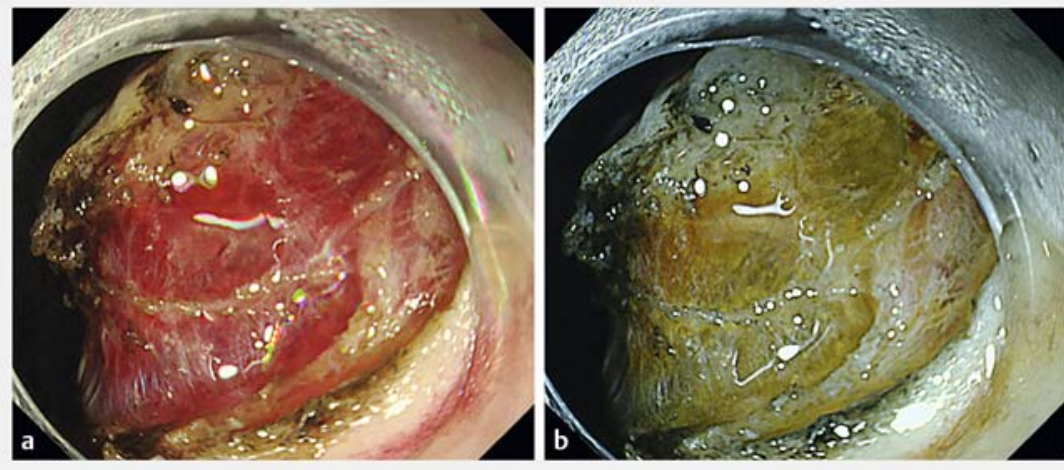

- Fig. 2 a Endoscopic image of the submucosal layer with severe hematoma observed using white light. b Endoscopic image of the submucosal layer with severe hematoma observed using red dichromatic imaging (RDI). The bleeding was visualized as yellow using RDI. The submucosal fibrous tissue was identifiable through the hematoma.
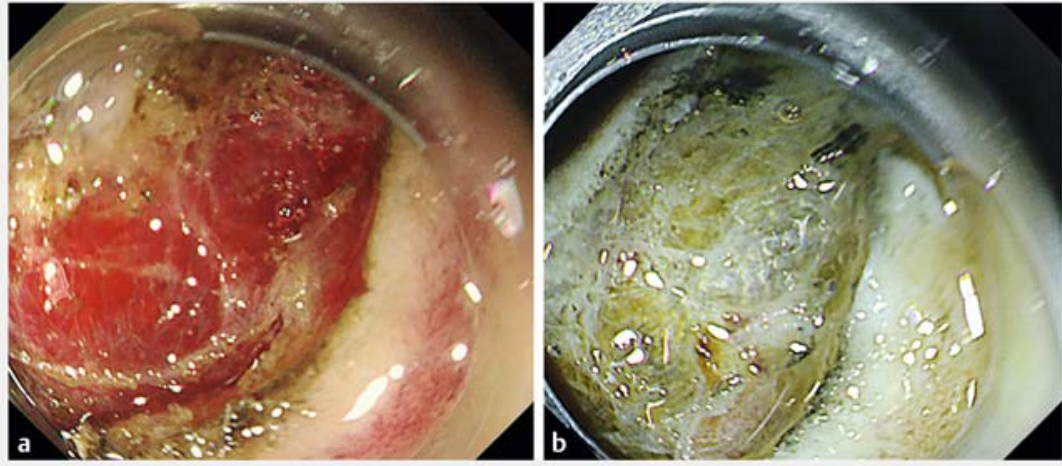

- Fig. 3 a Endoscopic image of the submucosal layer with severe hematoma observed using white light. b Endoscopic image of the submucosal fibrous tissue observed using RDI. The submucosal fibrous tissue showed whiter and clearer in the submucosal layer with hematoma.

this situation, identifying the submucosal fibrous tissue for dissection under white light ( $>$ Video 1; $>$ Fig. 2 a) was difficult. The white light imaging was then switched to RDI, and the submucosal fibrous tissue could be visualized more clearly ( $\mathbf{F i g} \cdot \mathbf{2}$ b). The submucosal layer was dissected and the tumor finally resected en bloc.

In this case, the submucosal fibrous tissue was identified because it showed whiter using RDI than under normal white light imaging ( $\mathbf{F i g . 3}$ ), and the bleeding was visualized as yellow on RDI. Thus, the submucosal fibrous tissue could be identified through the hematoma, and was dissected despite the presence of the hematoma. Another advantage of RDI is that it keeps the endoscopic view clearer during ESD with submucosal fatty tissue [5]. We believe that RDI is useful for dissecting submucosal fibrous tissue in the submu- 


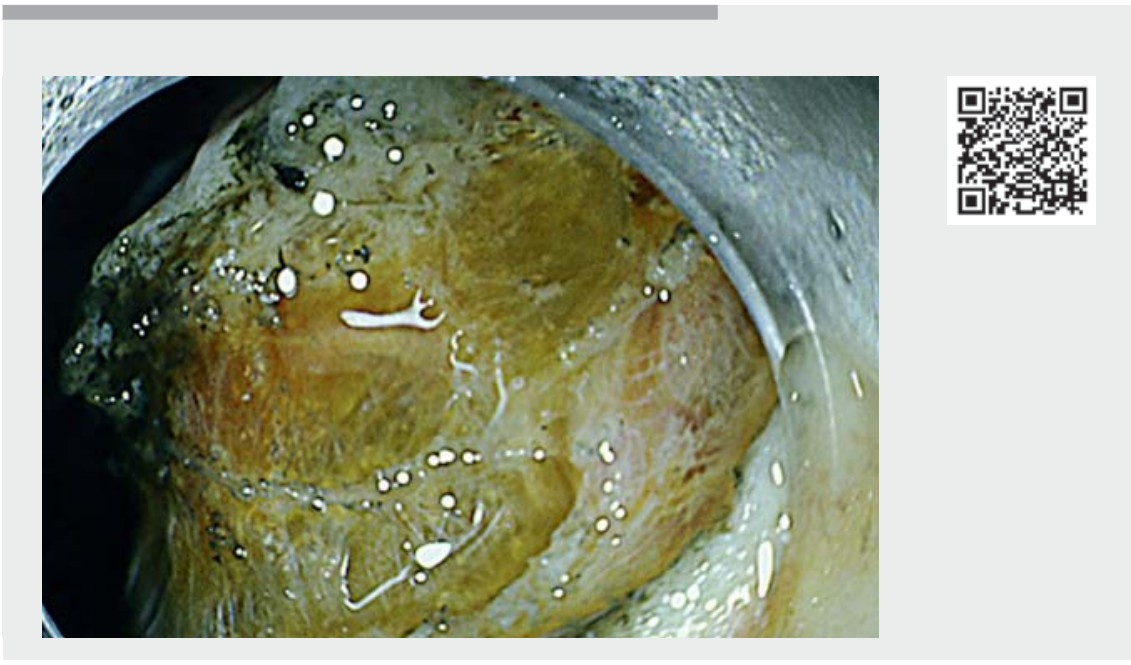

$\checkmark$ Video 1 Endoscopic submucosal dissection for gastric tumor in a 72 -year-old man. The submucosal fibrous tissue could be identified more clearly in the submucosal layer with hematoma using red dichromatic imaging.

cosal layer with hematoma during gastric ESD.

Endoscopy_UCTN_Code_CCL_1AB_2AD_3AF

\section{Competing interests}

The authors declare that they have no conflict of interest.

The authors

Shuichi Miyamoto ${ }^{1,2}$, Tomohiko R. Ohya ${ }^{3}$, Kaori Nishi ${ }^{4}$, Satoshi Abiko ${ }^{\circledR}{ }^{\odot}$, Ryo Sugiura ${ }^{1}$, Yoshiya Yamamoto ${ }^{1}$, Naoya Sakamoto ${ }^{2}$

1 Department of Gastroenterology and Hepatology, Hakodate Municipal Hospital, Hakodate, Japan

2 Department of Gastroenterology and Hepatology, Hokkaido University Faculty of Medicine and Graduate School of Medicine, Sapporo, Japan
[2] Kubosawa Y, Mori H, Fujimoto A. Utility of dual red imaging for endoscopic hemostasis of gastric ulcer bleeding. Dig Dis 2020; 38: 352-354

[3] Ninomiya Y, Oka S, Tanaka S et al. Clinical impact of dual red imaging in colorectal endoscopic submucosal dissection: a pilot study. Therap Adv Gastroenterol 2016; 9: 679-683

[4] Fujimoto A, Saito Y, Abe $S$ et al. Haemostasis treatment using dual red imaging during endoscopic submucosal dissection: a multicentre, open-label, randomised controlled trial. BMJ Open Gastroenterol 2019; 6: e000275

[5] Tanaka H, Oka S, Tanaka S et al. Dual red imaging maintains clear visibility during colorectal endoscopic submucosal dissection. Dig Dis Sci 2019; 64: 224-231

Bibliography

Endoscopy 2021; 53: E413-E414

DOI 10.1055/a-1333-0831

ISSN 0013-726X

published online 14.1.2021

(c) 2021. Thieme. All rights reserved.

Georg Thieme Verlag KG, Rüdigerstraße 14, 70469 Stuttgart, Germany

4 Department of Nursing, Hakodate Municipa Hospital, Hakodate, Japan

Corresponding author

\section{Shuichi Miyamoto, MD, PhD}

Department of Gastroenterology and Hepatology, Hakodate Municipal Hospital, 1-10-1, Minato-cho, Hakodate, 041-8680, Japan shuichi0210miyamoto@yahoo.co.jp

\section{References}

[1] Yahagi N, Fujimoto A, Horii ] et al. Dual red imaging: a novel endoscopic imaging technology visualizing thick blood vessels in the gastrointestinal wall. Endosc Int Open 2019; 7: E1632-E1635

\section{ENDOSCOPY E-VIDEOS \\ https://eref.thieme.de/e-videos}

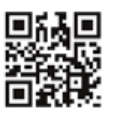

Endoscopy E-Videos is a free access online section, reporting on interesting cases and new techniques in gastroenterological endoscopy. All papers include a high quality video and all contributions are freely accessible online.

This section has its own submission website at https://mc.manuscriptcentral.com/e-videos 